\title{
LA BANDA MILITAR DE ALAJUELA Y SU PAPEL COMO DIFUSORA DE MÚSICA NACIONAL ENTRE 1938-1946. ANÁLISIS DE LAS BITÁCORAS DE TRABAJO
}

\author{
Mauricio Araya Quesada \\ Universidad de Costa Rica
}

Recibido: 16-12-2016

Aprobado: 28-2-2017

Profesor en la Sede de Occidente de la Universidad de Costa Rica,

Departamento de Filosofía, Artes y Letras. Magister en Música con énfasis en Dirección de Banda. Fue director titular de la Banda de Conciertos de Alajuela y fungió como Director General de Bandas del Gobierno de Costa Rica. maraya@conservatoriodeoccidente.com

\section{RESUMEN}

Las bandas militares del gobierno de Costa Rica tuvieron un papel protagónico y sobresaliente en el desarrollo musical de la nación. Los trabajos investigativos sobre la evolución y progreso de la música costarricense han tenido que contemplar apartados sobre la historia de esas agrupaciones musicales. Los directores y músicos mayores debían llevar un control estricto sobre el trabajo realizado; para ello llenaban bitácoras oficiales con información sobre el repertorio ejecutado, el manejo de personal y los castigos, los inventarios de activos y el archivo de partituras. Esas bitácoras son fuentes primarias desconocidas que deben quedar disponibles, para realizar investigaciones las cuales aporten datos históricos relevantes. Así, por ejemplo, gracias a ellas, el presente trabajo podrá establecer una base historiográfica con el fin de reconstruir un marco histórico referencial sobre la importancia de la Banda Militar de Alajuela como difusora de música nacional.

Palabras clave: Música costarricense, historia de Costa Rica, Bandas del gobierno de Costa Rica, cultura musical de Costa Rica, Banda Militar de Alajuela.

\begin{abstract}
:
The military bands of the Government of Costa Rica had a leading and remarkable role in the country's musical development. The research work regarding the evolution and progress of Costa Rican music have had to consider sections of the story of these musical groups. The Directors and Major Musicians (Deputy Directors) had to keep detailed records of the work done; for this they kept official logbooks with information regarding the repertoire which was played, the handling of personnel and sanctions, asset inventories, and filing of musical scores. These logbooks are unknown primary sources which must remain available for research, so as to provide relevant historical data. So, for example, thanks to these, the present work will be able to establish a historiographic basis, so as to be able to reconstruct a reference historical framework about the importance of the Military Band of Alajuela, as a disseminator of national music.
\end{abstract}

Key words: Costa Rican music, history of Costa Rica, Costa Rican government bands, Costa Rican musical culture, Military Band of Alajuela. 
En un artículo escrito anteriormente ${ }^{1}$ se realizó una introducción general sobre el proyecto investigativo que ha dado oportunidad a una discusión continua sobre la historiografía de las bandas militares de Costa Rica a través de sus "bitácoras de trabajo". En vista de que ese proyecto se va desarrollando por fases, la primera fue enfocada en la Banda Militar de Alajuela y su papel como difusora de música nacional; se mostró de manera resumida el perfil del proyecto, en donde quedaron claras las intenciones, un estado de la cuestión, una breve explicación sobre el enfoque conceptual, varias preguntas de investigación, delimitaciones, metodologías, información relevante de las fuentes consultadas y algunos resultados preliminares como ejemplos de los primeros aportes del proyecto. Este nuevo texto pretende continuar con la discusión brindando un marco histórico de referencia de la Banda Militar de Alajuela y algunos resultados estadísticos de su trabajo en la difusión de música costarricense.

\section{BANDAS MILITARES EN COSTA RICA Y SUS BITÁCORAS DE TRABAJO}

Se llama bandas militares de Costa Rica a las siete bandas del gobierno de ese país que fueron supervisadas por la Dirección General de Bandas del Departamento de Guerra y Marina, desde antes de 1845 hasta 1948. Con la abolición del ejército, este departamento desapareció, por lo que dichos grupos se trasladaron al Ministerio de Seguridad Pública, ahí se les dio el nombre de Bandas Nacionales. En 1972, pasaron al Ministerio de Cultura, Juventud y Deportes ${ }^{2}$ y a partir del año 2009 se les denominó Bandas de Conciertos.

Lo denominado "bitácoras de trabajo" son documentos también importantes para la historiografía de las bandas militares, estos no

\footnotetext{
1 Araya, Mauricio. "La Banda Militar de Alajuela y su papel como difusora de música nacional. Análisis de las bitácoras de trabajo 1938-1946. Introducción y resultados preliminaries". Universidad de Costa Rica-Sede de Occidente, Revista Pensamiento Actual-Volumen 16-Número 27, 2016, ISSN Impreso: 1409-0112/ISSN Electrónico: 22153586.

2 Más información sobre la base histórico-administrativa de las bandas en: "Procuraduría General de la República. Dictamen 198 del 18 de mayo de 2006. Dirigido a la ministra de cultura María Elena Carballo Castegnaro, en respuesta al oficio DM-574-2005 del 29 de abril del 2005, signado por el anterior Ministro, Sr. Guido Sáenz González".
} 
han sido aún objeto de estudio, por ejemplo, los "libros de programas" que contabilizan el repertorio ejecutado por estos grupos, los "catálogos de obras", los "libros de manejo de personal y de castigos". Con esas bitácoras se podrán conocer los músicos activos en ese periodo, las obras costarricenses programadas, los compositores de estas, las obras disponibles en los archivos de música, las acciones disciplinarias, las comunidades visitadas, los servicios que realizaron las bandas, etc.

Las siguientes son las bitácoras encontradas de la Banda Militar de Alajuela, las cuales han suministrado datos importantes para esta investigación: Libro de programas, 1 de mayo de 1938; Libro de programas, 1 de agosto de 1951; Nuevo régimen 19361940 Alajuela, 8 de mayo, Inventario general de la Banda Militar, Movimiento de altas, bajas descensos, traslados, cambios de instrumentos, etc., a cargo de Manuel Alberto Coto Cedeño; Inventario de útiles pertenecientes a la Banda Militar de Alajuela,1905; Banda Militar de Alajuela; Movimiento disciplinario durante el mes de abril, 1930; Catálogo de música, Banda Militar de Alajuela año 1936, arreglado por Juan José Leitón y Cuaderno de castigos del cuerpo de banda, entregado por la comandancia de plaza el 15 de agosto de 1934 y llevado por Arcelio Chávez.

Las publicaciones sobre la música en Costa Rica y las bandas militares han aportado datos relevantes; no obstante, las "bitácoras de trabajo" de las bandas militares no fueron consultadas, por lo que quedó de lado información indispensable para reconstruir la historia de estos grupos y confrontar las historias de dominio académico y empírico sobre su impacto. Gracias a los contenidos de esos documentos oficiales, se puede definir que las bandas fueron difusoras de música costarricense e internacional, brindaron educación musical a sus músicos y oyentes, y ofrecieron esparcimiento artístico gratuito con cobertura en las siete provincias de Costa Rica; eso las posicionó desde 1845 como las instituciones culturales más importantes del Estado costarricense, antes de la creación de la Orquesta Sinfónica Nacional y del Ministerio de Cultura, Juventud y Deportes.

En este nuevo texto, la premisa será discutir sobre el papel de la Banda Militar de Alajuela en la difusión de obras, en especial las costarricenses, de tal manera que se tome en cuenta además a los autores, los géneros musicales y la proyección de la música en general, como un valor estético que se redistribuye y posiciona 
observando la cultura en relación con el poder, el consumo y la educación musical. ${ }^{3}$

\section{RESEÑA HISTÓRICA DE LA BANDA DE ALAJUELA Y SUS SUCESIONES ADMINISTRATIVAS}

Realizar una reseña histórica de la Banda de Alajuela es indispensable para el presente estudio, debido a que los antecedentes históricos ofrecerán una mirada más amplia desde el punto de vista cronológico. Además, conocer la sucesión de directores y músicos mayores acercará directamente al punto central del problema: la difusión de la música de autores costarricenses realizada por estos personajes y su grupo a través de sus programaciones semanales.

El historiador Pompilio Segura es quien ha investigado con más detalle el desarrollo de las bandas militares del Estado costarricense desde antes de la segunda mitad del siglo XIX. Su trabajo constituye la fuente que relata con minuciosidad los acontecimientos históricos de la banda de Alajuela. Por lo tanto, corresponde transcribir algunos datos suministrados por él, con la finalidad de visualizar una línea histórica continua, con énfasis en las sucesiones administrativas de la banda. La información brindada por Segura se logró completar con los datos extraídos de los libros de movimientos de personal desde 1905 hasta 1969.

Sobre los inicios, Pompilio Segura relata que en el mes de marzo de 1843 se reorganizaron las milicias nacionales y se dispuso que la banda de Alajuela debiera integrar más instrumentos melódicos. Como el gobernante José María Alfaro era alajuelense, quiso dar a su ciudad cierta ventaja, y ya para inicios de ese año había logrado organizar un ensamble de esta naturaleza bajo la dirección de Pedro Barahona.

Con la llegada de José Martínez en 1845, músico de origen español quien fue contratado para brindar formación musical a los músicos de las bandas, algunos integrantes de la banda de Alajuela se trasladaron a San José a prepararse. Cuando venció el

\footnotetext{
${ }^{3}$ Más sobre el marco conceptual en: Araya, Mauricio. "La Banda Militar de Alajuela y su papel como difusora de música nacional. Análisis de las bitácoras de trabajo 1938-1946. Introducción y resultados preliminaries". Universidad de Costa Rica-Sede de Occidente, Revista Pensamiento Actual-Volumen 16-Número 27, 2016, ISSN Impreso: 1409. 0112/ISSN Electrónico: 2215-3586. p. 76-77-78.
} 
contrato de Martínez, se nombró a Francisco Llibons como nuevo director de la Música Marcial del país. Llibons instó a continuar con esa tarea, por lo que un número de 15 músicos de Alajuela regresó a San José para continuar el aprendizaje musical.

En 1847, el jefe de Estado José María Castro Madriz decidió trasladar a la capital el armamento de las provincias de Heredia, Cartago y Alajuela, por lo que las bandas se quedaron sin instrumental. Fue entonces cuando la municipalidad de Alajuela "acordó fundar una escuela de música para preparar jóvenes que se hicieran cargo principalmente de amenizar los oficios religiosos" ${ }^{\prime 4}$. Esta escuela fue dirigida primero por José María Acevedo Sandino, luego por Pedro Barahona y finalmente por Casimiro Chávez. Así, según lo anterior, Alajuela permaneció catorce años sin banda. Ya para el año 1861 se le encomendó la tarea de restablecer las bandas de Heredia y Alajuela a Manuel María Gutiérrez, director de Música Marcial de aquella época. Entonces, en 1861 se nombró como director a Buenaventura Alcázar, quien fue destituido injustamente por no ser simpatizante del gobierno de Tomás Guardia, por lo que el 29 de abril de 1870 se nombró de inmediato a Lorenzo Fernández Bonilla como sucesor.

En el año 1873 el número de músicos pasó desde 18 hasta 24, hecho que demuestra el fortalecimiento del grupo. Asimismo, en 1875 se eximió a los músicos de dormir en el cuartel, lo cual ocurría desde 1843. Ese acuerdo; no obstante, se fue incumpliendo pues muchas noches se les obligaba a los músicos dormir en el cuartel "con sus rifles en mano". 5

Según relata Segura, "el público se hallaba informado de las piezas que se tocaban y de sus autores, pues desde el mes de mayo de 1882 Lorenzo Fernández divulgaba los programas de los conciertos en el periódico alajuelense de la época"6. El hecho de publicitar los eventos y las obras por ejecutar en un medio de comunicación masivo supone que incluso la población que no asistía a las presentaciones tuvo acceso a la información sobre compositores y composiciones del repertorio programado por la

\footnotetext{
${ }^{4}$ González Dobles, Jaime. La patria del tico: interpretación del ser costarricense. San José Costa Rica: Logos editorial, Editorial Antares, 1995. Página 44.

${ }^{5}$ González Dobles, Jaime. La patria del tico: interpretación del ser costarricense. San José Costa Rica: Logos editorial, Editorial Antares, 1995. Ibid, 53.

${ }^{6}$ Ibid, p. 55, 56.
} 
banda. Fernández murió en 1900 sin tener la oportunidad de ejecutar conciertos en el quiosco, porque "las retretas se realizaban en la esquina noroeste de la antigua plaza principal, frente al cuartel de hoy". ${ }^{7}$

Después de Lorenzo Fernández, asumió el mando el alemán Rosendo G. Rotschild, director de bandas y orquestas en México y Guatemala. Rotschild dirigió la banda de Alajuela a partir del 23 de julio de 1900, por un año y medio. Luego fue sustituido por el compositor y director español Lucio de Avendaño, en marzo de 1902. ${ }^{8}$ En abril de 1904, llegó a la dirección de la banda de Alajuela Carlos María Gutiérrez Rodríguez, hijo de José María Gutiérrez.

Ese dato se puede corroborar en la bitácora Inventario de útiles pertenecientes a la Banda Militar de Alajuela. Primera fecha indicada en el libro, 1905 en la página 4. Ahí se ve claramente la

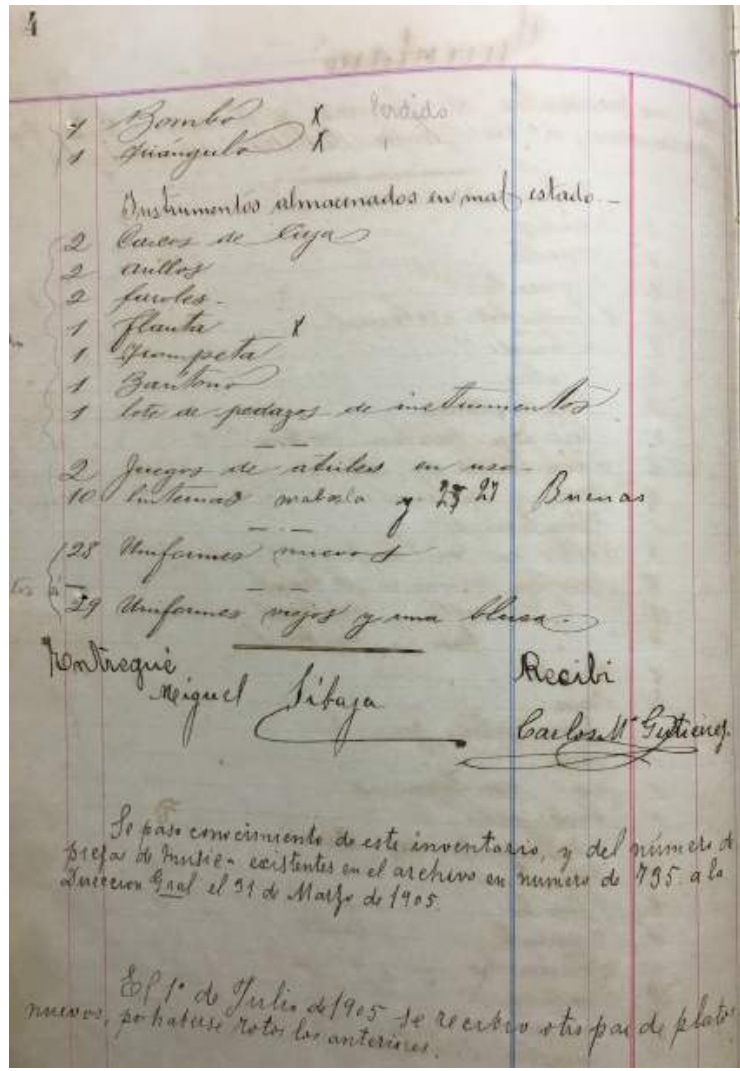

Fotografía 1. Página 4, Inventario de útiles pertenecientes a la Banda Militar de Alajuela, 1905. firma de recibido del inventario de útiles a Miguel Sibaja por parte de Carlos María Gutiérrez, quien comunica en ese libro que se dio a conocer dicho inventario y un número de 795 piezas musicales a la Dirección General de Bandas.

Al renunciar Carlos María Gutiérrez al cargo en 1906, lo sustituyó Eduardo Cuevas Morales, quien fungió hasta su muerte en 1913. Cuevas llegó al país como director de orquesta de una compañía de zarzuela. Este dato también se puede corroborar, pues en la

\footnotetext{
${ }^{7}$ Segura, 63.

8 Ibid, p.64.
} 
bitácora Inventario de útiles pertenecientes a la Banda Militar de Alajuela, 1905, en la página 5, se puede ver la firma de Cuevas que da por recibido un grupo de instrumentos.

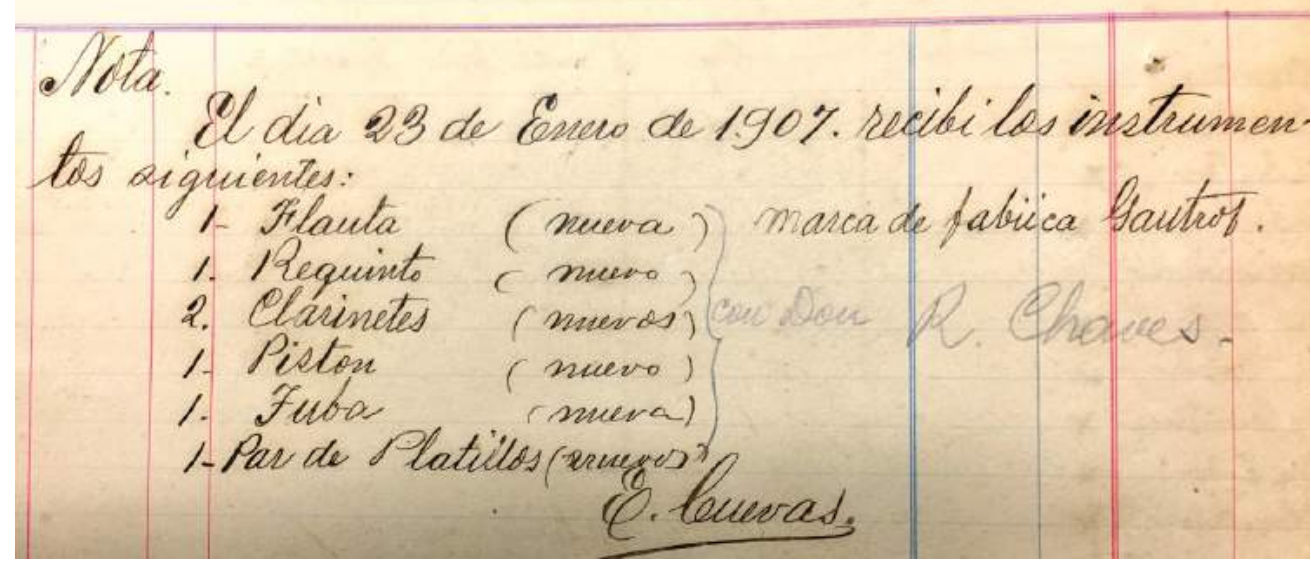

Fotografía 2. Recorte página 5, Inventario de útiles pertenecientes a la Banda Militar de Alajuela, 1905.

E

El trabajo investigativo de Segura se circunscribió al desarrollo musical en Costa Rica logrado a través de las bandas militares en el siglo XIX, y por lo tanto su estudio sobre la Banda Militar de Alajuela llegó hasta la gestión de Eduardo Cuevas. De acuerdo con la investigación realizada por Roberto Le Franc Ureña, se tiene conocimiento de que Alfredo Morales sustituyó por un breve periodo en 1913, como director, al maestro Cuevas.

Ludmila Svatec, en su libro Juan Loots, cuenta que en 1913 falleció Eduardo Cuevas y después de un corto periodo, la dirección fue ocupada por Alfredo Morales, en ese mismo año ascendieron a Emilio León Rojas como director, pero luego fue sustituido en 1915 por Isaac Barahona, quien fungió hasta octubre de 1919, fecha en que fue sustituido por Jesús Mora en 1922. En noviembre, se encuentra otro cambio de director, pues al renunciar Jesús Mora, es sustituido por Manuel Alberto Coto. Posteriormente, a partir de 1925, se nombró a Víctor Sanabria, y fungió como músico mayor Segundo Romo, quien había sustituido a José Coto. Es importante aclarar que no es claro de dónde proviene esta información, pues la escritora del libro no colocó referencias ni bibliografía. 
Los datos anteriores no coinciden con los extraídos del libro de Pompilio Segura, pues gracias a una fotografía de la banda de Alajuela en 1917, utilizada como ilustración en el libro ${ }^{9}$ y según el reconocimiento que él mismo hace de los integrantes, parece que el director en 1917 era Rafael Conejo y el músico mayor Otoniel Badilla.

Según Jorge Sanabria, de 1928 a 1932 quien estuvo a cargo de la banda militar de Alajuela fue Víctor Manuel Sanabria León. Jorge Sanabria es sobrino de Víctor Manuel y ha realizado estudios genealógicos y biográficos de su tío ${ }^{10}$. Una vez más, los datos de Jorge Sanabria no coinciden con los de Svatec, pues ella afirma que Víctor Manuel inició como director en Alajuela en 1925. También, en la bitácora Banda Militar de Alajuela. Movimiento disciplinario durante el mes de abril, 1930, se describe una acción disciplinaria "con motivo al cambio de Dirección de esta banda".

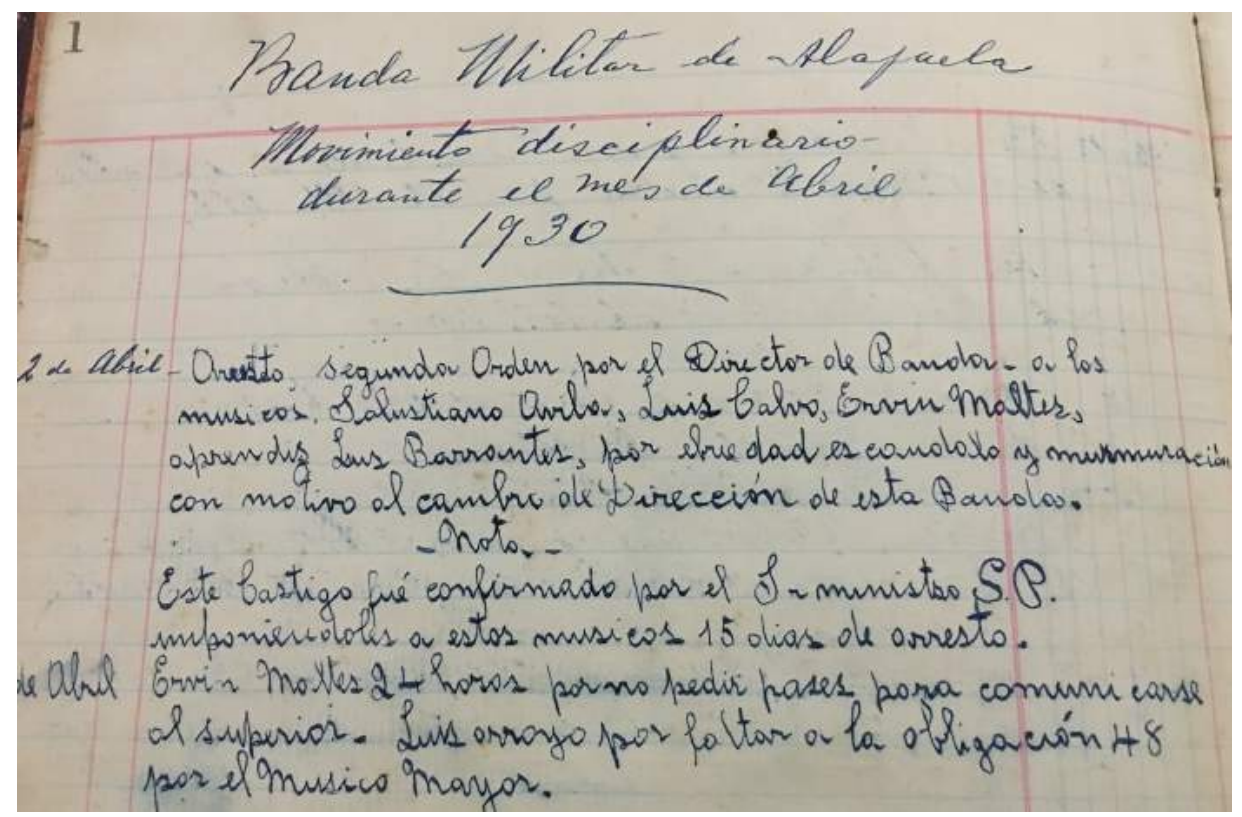

Fotografía 3. Recorte página 1, Libro Movimiento disciplinario durante el mes de julio de 1931, Banda Militar de Alajuela.

\footnotetext{
${ }^{9}$ Segura, 61.

${ }^{10}$ Entrevista realizada a Jorge Sanabria por el Dr. Jorge Carmona vía correo electrónico, el 30 de octubre de 2014.
} 
Según el cambio de régimen especificado en la página 17 de la bitácora antes mencionada, quien firmaba como director era Alcides Prado Quesada, de acuerdo con título de la página: "Movimiento disciplinario durante el mes de julio de 1931". Esto se confirma en la página 20, en donde también se describe que el 8 de mayo de 1932, por el cambio de gobierno, llegó la orden de traslado del maestro Alcides Prado Quesada a Puntarenas, y el nombramiento de Manuel Alberto Coto para la banda de Alajuela.

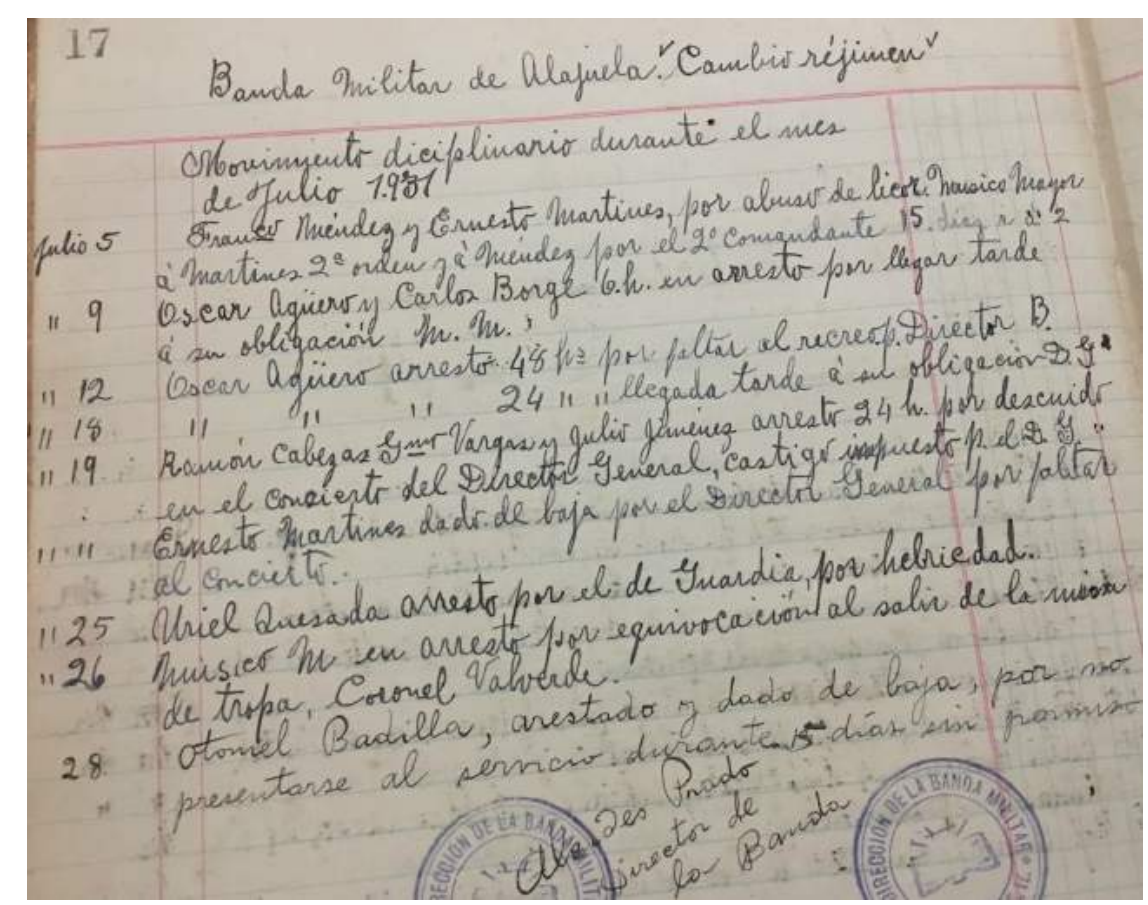

Fotografía 4. Recorte página 17, Libro Movimiento disciplinario durante el mes de junio de 1931, Banda Militar de Alajuela.

En la biografía de Alcides Prado, realizada por su hija Zaida Prado para el archivo histórico musical de la Escuela de Artes musicales de la Universidad de Costa Rica, se describe que él entró como director de la banda de Alajuela en $1931^{11}$. Además, en el libro La gran aventura musical de Alcides Prado, escrito por Yehudi Monestel Arce, en las páginas 59 y 60 dice:

\footnotetext{
"En el año 1931, el "Proyecto Panamá" llegó a su final y Alcides Prado, su esposa Carmen, su hija María de los Ángeles y sus hermanos, regresaron a Costa Rica. El Director General de Bandas, José Santiesteban Repetto, nombró a Alcides como Director de la Banda Militar de Alajuela y durante todo un año, cumplió su labor, avanzando un programa de perfeccionamiento para los músicos y renovando el repertorio del grupo. Pasados doce meses puso punto final a su compromiso con el Maestro Repetto y se dedicó, por entero, a rearmar la Orquesta Alcides Prado..."
}

\footnotetext{
${ }^{11}$ Disponible en archivomusical.ucr.ac.cr
} 
Con la aparición del libro Nuevo Régimen 1936-1940 Alajuela 8 de mayo, Inventario general de la Banda Militar, Movimiento de Altas, Bajas, descensos, traslados, cambios de instrumentos etc., a cargo de Manuel Alberto Coto Cedeño se ha logrado ubicar a los directores y algunos músicos mayores hasta 1952. Por lo tanto, al buscar información en esa fuente, se encontraron los siguientes datos textuales que dan fe de los nombramientos de los mandos de la agrupación:

"Por acuerdo número 15 del 20 de julio de 1934 fui nombrado músico mayor de la Banda Militar de Alajuela, firma Arcelio Chávez. ${ }^{12}$ Sin embargo: El 1 de marzo de 1935, aceptada la permuta al Sr Arcelio Chavez con el Sr Rafael Castro, el primero para la Banda de San José y el segundo a la Banda de Alajuela. ${ }^{13}$

Así, según consta en el libro de control de personal mencionado anteriormente ${ }^{14}$, para el 8 de mayo de 1936 se tenía la lista de integrantes de la banda, entre la que figuran Manuel Alberto Coto Cedeño como director y Rafael Castro Alvarado como músico mayor. Además, al continuar revisando los cambios de personal se encontró la siguiente información:

- El 15 de marzo de 1937 fue nombrado músico mayor Carlos Torres. ${ }^{15}$

- El 17 de mayo de 1942 fue dado de alta como director de esta Banda Militar el Sr Jesús Bonilla Chavarría. ${ }^{16}$

- El 15 de junio del 1951 se encontraba como director Rafael Castro, según el dato textual: "entregado para estudiar un método de clarinete al Sr. Jorge L. Calvo P. en vía de préstamo, orden del Sr. Director R. Castro". ${ }^{17}$

- En Junio 12 de 1952, murió el Sr Director de la Banda don Rafael Castro Alvarado y pasó a director el Sr. Músico mayor don Carlos Torres. ${ }^{18}$

- El profesor Antonio González Carballo fue nombrado director de esta Banda el día 16 de julio de 1969. ${ }^{19}$

\footnotetext{
${ }^{12}$ Este dato fue tomado del Cuaderno de castigos del cuerpo de banda entregado por la comandancia de plaza el 15 de agosto de 1934 para que fuera llevado por Arcelio Chávez.

${ }^{13}$ Nuevo Régimen 1936-1940 8 de mayo. Inventario general de altas, bajas, descensos, traslados, cambios de instrumentos etc., 9.

14 Ibid, p. 1

15 Ibid, p. 12

${ }^{16}$ Ibid, p. 15

${ }^{17}$ Nuevo Régimen 1936-1940 8 de mayo. Inventario general de altas, bajas, descensos, traslados, cambios de instrumentos, etc.,.24

18 Ibid, p.26

19 Libro de Partes y programas de conciertos. Archivo Banda de Alajuela. Escrito por Marco Tulio Corao Velázquez, 1.
} 


\section{COMPOSITORES Y OBRAS NACIONALES EJECUTADAS POR LA BANDA MILITAR DE ALAJUELA ENTRE 1938 Y 1946}

En lo que respecta al análisis del repertorio y para determinar de manera cuantitativa cuál fue el volumen de obras costarricenses interpretadas entre 1938 y 1936 y cuáles fueron los compositores de estas, se utilizará primordialmente el Libro de programas 1 de mayo de 1938.

Gracias a la información extraída de ese libro, se ha podido crear una lista de autores costarricenses y obras ejecutadas en ese periodo. En algunos casos se tiene información del día del estreno de la pieza musical y en otros también del repertorio llevado a sitios distintos al lugar habitual en donde se realizaban las retretas, recreos y misas. Sin embargo, el simple hecho de establecer un listado de músicos y obras cumple cabalmente con el objetivo de dar a conocer nombres que han estado en el anonimato y obras que han permanecido olvidadas desde ese entonces.

Una investigación posterior podrá corroborar qué piezas musicales existen aún en el archivo de partituras de la banda, así como cuáles de ellas no están ubicables actualmente. Si bien es cierto, el archivo musical de la banda de Alajuela se encuentra en constante uso, las obras listadas en esta investigación deberían encontrarse ahí. No obstante, se sabe que los controles han sido poco estrictos en el resguardo de las partituras y ha existido una libre administración que músicos, músicos mayores y directores han tenido de los archivos musicales de todas las bandas del país. Por lo tanto, realizar un monitoreo de las obras existentes actualmente en la biblioteca de música de la banda de Alajuela, revisar los catálogos de obras, revisar en otras bases de datos, como la del Archivo Histórico Musical de la Universidad de Costa Rica, el Archivo Nacional, la Biblioteca Nacional, archivos particulares y los archivos de las restantes seis bandas del país será una tarea pendiente.

En la publicación anterior se mencionó que de las fuentes bibliográficas también se han podido extraer listas de obras de compositores nacionales ejecutadas por las bandas. Estos datos, ya corroborados por los distintos autores de los libros consultados, son una fuente importante para consolidar y fortalecer la información sobre algunas piezas encontradas en el libro de 
programas. Así en el artículo mencionado se colocaron: una lista de obras de Juan Morales, Gordiano Morales, Octavio Morales y Alfredo Morales recopilada por Roberto Le Franc Ureña y otra de obras tomadas de un manuscrito de Manuel María Gutiérrez, suministrada por Carlos Meléndez Chaverri. ${ }^{20}$ Además, Ludmila Svatec, en su libro Juan Loots, en el capítulo cuarto, habla de las composiciones costarricenses dedicadas a las bandas entre los años 1907 y 1929. También, Bernal Flores, en su libro Julio Fonseca, deja disponible en el anexo XIV una publicación de don Julio tomada de la Revista Musical, año dos, 2 de julio de 1941, número cuatro. "Apuntes sobre música costarricense". Número dos, "Agrupaciones artísticas", 21 en ese texto se encuentra una lista de autores que él maestro Fonseca considera importantes de mencionar: ${ }^{22}$

Los compositores mencionados en esas fuentes y otros más encontrados en el libro de María Clara Vargas ${ }^{23}$ se deben conocer para tener una referencia que sirva de punto de partida sobre los autores activos en el siglo XIX y la primera mitad del siglo XX, muchos de esos personajes estuvieron vinculados a las bandas. Esos listados ${ }^{24}$ servirán para realizar un análisis comparativo y determinar así el aporte cuantitativo de estos investigadores con respecto al número de compositores y obras que estuvieron presentes en la primera mitad del siglo $\mathrm{XX}$, pues el Libro de

\footnotetext{
${ }^{20}$ Araya, Mauricio. "La Banda Militar de Alajuela y su papel como difusora de música nacional. Análisis de las bitácoras de trabajo 1938-1946. Introducción y resultados preliminaries". Universidad de Costa Rica-Sede de Occidente, Revista Pensamiento Actual-Volumen 16-Número 27, 2016, ISSN Impreso: 1409-0112/ISSN Electrónico: 22153586. p. $84-85$

${ }^{21}$ Flores, Bernal. Julio Fonseca. Datos sobre su vida y análisis de su obra. San José, Costa Rica. Ministerio de Cultura, Juventud y Deportes, 1973.

${ }^{22}$ Anexo número XIV del libro: Flores, Bernal. Julio Fonseca. Datos sobre su vida y análisis de su obra. San José, Costa Rica. Ministerio de Cultura, Juvendud y Deportes, 1973. Tomado de una publicación de don Julio en la Revista Musical, año dos, 2 de julio de 1941 número cuatro. "Apuntes sobre música costarricense". Número dos, "Agrupaciones artísticas".

${ }^{23}$ Vargas Cullell, María Clara. De las fanfarrias a las salas de concierto: música en Costa Rica, 1840-1940. San José, Costa Rica: Editorial de la Universidad de Costa Rica, 2004. p. 283.

${ }^{24}$ Las aportadas por María Clara Vargas, Roberto Le Franc y Carlos Meléndez ya fueron publicadas en: Araya, Mauricio. "La Banda Militar de Alajuela y su papel como difusora de música nacional. Análisis de las bitácoras de trabajo 1938-1946. Introducción y resultados preliminares". Universidad de Costa Rica-Sede de Occidente, Revista Pensamiento ActualVolumen 16-Número 27, 2016, ISSN Impreso: 1409-0112/ISSN Electrónico: 2215-3586.
} 
programas 1938-1946 brindó dos listas de compositores y obras, ${ }^{25}$ con más de cincuenta autores, la mayoría desconocidos.

Por otra parte, tabular la información del Libro de programas antes mencionado ayudó a extraer datos que se sumarán a los ya aportados por otros investigadores; además, este ejercicio permitió, entre otras cosas, observar la frecuencia con la que se ejecutaban las obras, eso evidenció la popularidad de algunas piezas musicales y de sus compositores. También se pudo determinar cuáles géneros musicales estaban de moda y cuáles autores se inclinaban por unos u otros. Como ya se mostró en las listas de autores recopiladas por María Clara Vargas, Roberto Le Franc, Ludmila Svatec y Julio Fonseca, existieron músicos y compositores reconocidos que acapararon la atención en la mayoría de trabajos investigativos sobre la música en Costa Rica; sin embargo, quedaron por fuera otros autores que lograron ejecutar música original, gracias a la banda militar de su provincia.

El siguiente gráfico contiene los nombres de los
compositores que tuvieron más participación en las programaciones entre 1938 y 1946. También se puede ver el número de veces que intervinieron con sus obras en los conciertos de esa época.

\footnotetext{
${ }^{25}$ Estas listas ya fueron publicadas en: Araya, Mauricio. "La Banda Militar de Alajuela y su papel como difusora de música nacional. Análisis de las bitácoras de trabajo 1938-1946. Introducción y resultados preliminaries". Universidad de Costa Rica-Sede de Occidente, Revista Pensamiento Actual-Volumen 16-Número 27, 2016, ISSN Impreso: 14090112/ISSN Electrónico: 2215-3586.
} 


\section{Compositores}

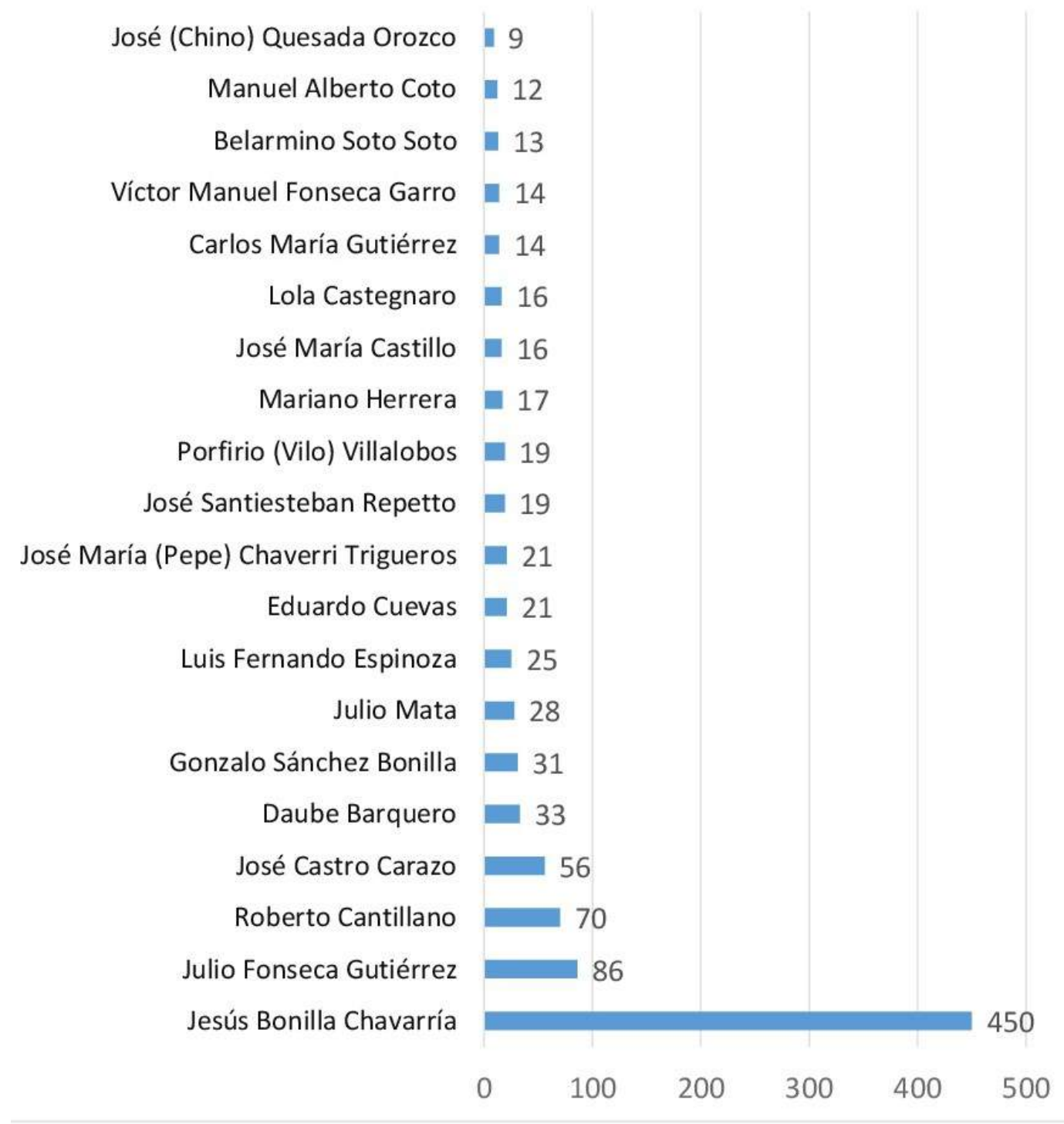

\section{Gráfico 1}

Autores y cantidad de veces que intervinieron con sus obras entre 1938 y 1946, Banda Militar de Alajuela.

Este otro gráfico muestra las veces que se programaron las obras de los diez compositores costarricenses más escuchados en las programaciones de la Banda Militar de Alajuela, entre 1938 y 1946. 


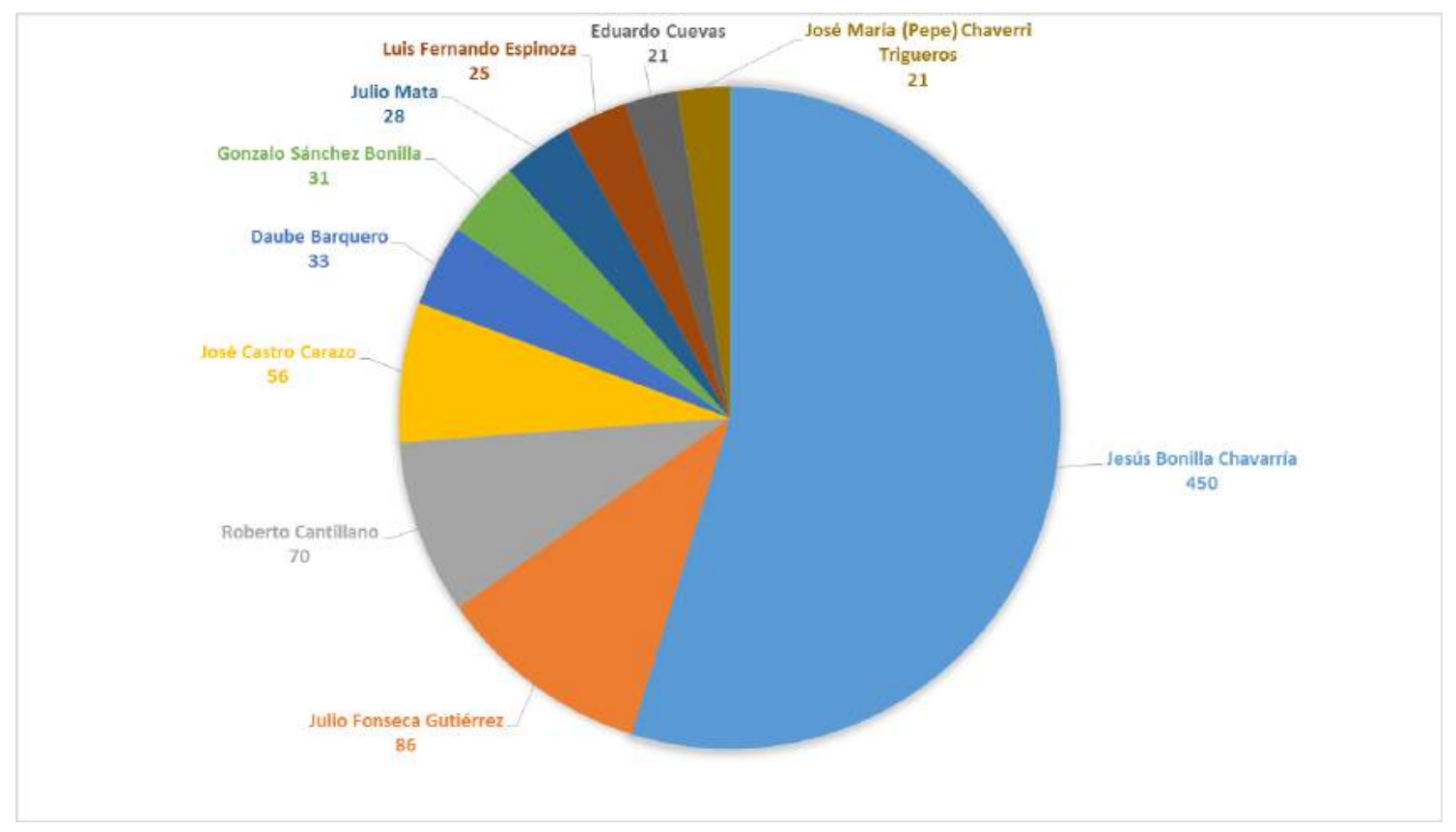

\section{Gráfico 2}

Diez compositores más programados, Banda Militar de Alajuela, 1938-1946.

Como se puede apreciar, dentro de las sucesiones administrativas de la Banda Militar de Alajuela se encuentra a Jesús Bonilla. Él y Julio Fonseca fueron los dos compositores cuyas obras se ejecutaron con más frecuencia en las programaciones entre 1938 y 1946. Bonilla tuvo la oportunidad de ver sus obras programadas cuatrocientas cincuenta veces.

También fue posible conocer cuáles fueron las obras que más veces se ejecutaron entre 1938 y 1946. Es importante destacar que aparecen varias piezas del compositor Jesús Bonilla, por lo que se debe tener en cuenta que este, al ser nombrado director de la banda desde 1942, tuvo la oportunidad de programar sus propias composiciones. Sin embargo, también es evidente que programaron obras de otros autores costarricenses. Eso se puede determinar observando el repertorio ejecutado entre 1942 y 1946. 


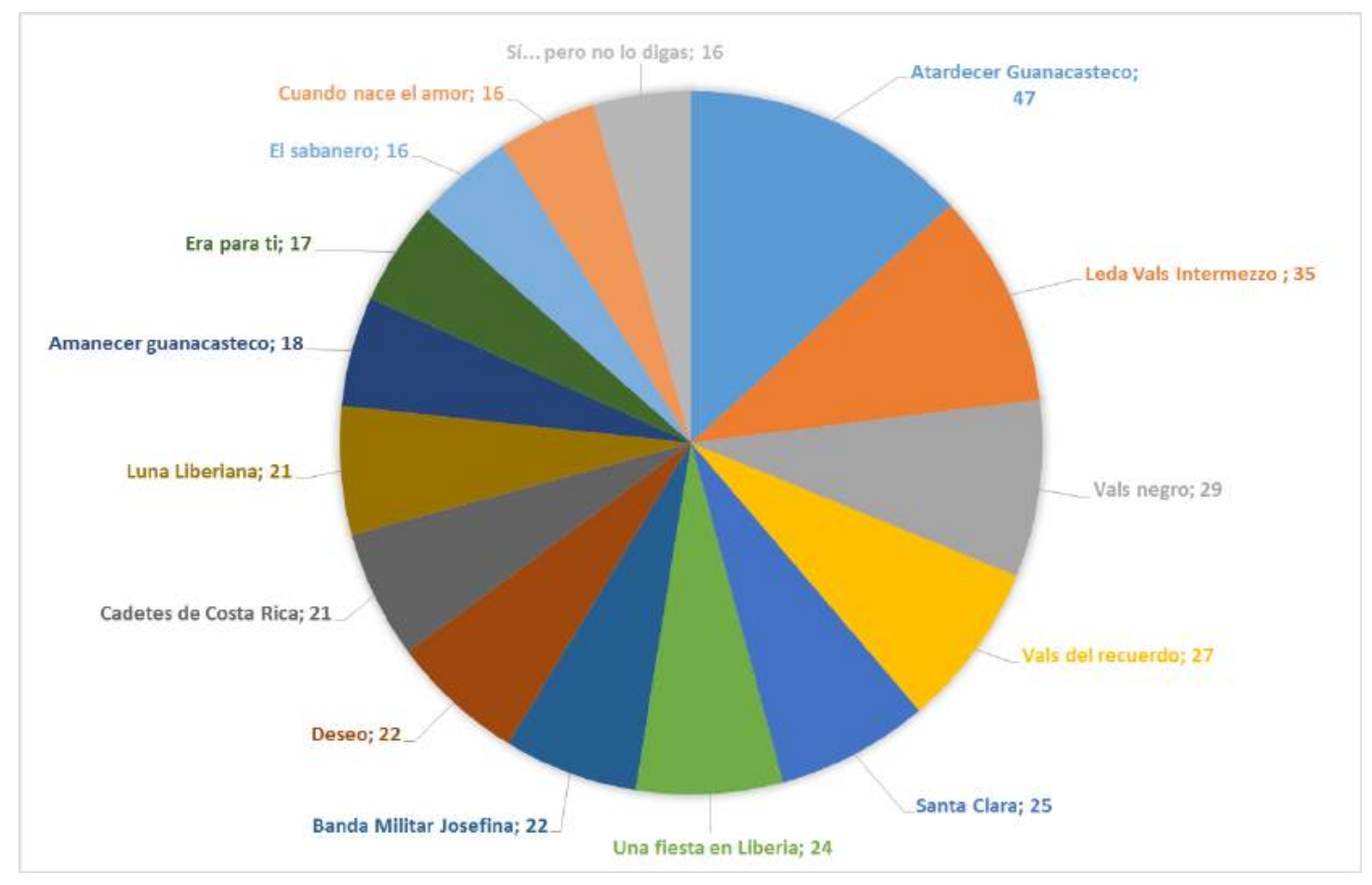

Gráfico 3.

Obras más programadas, Banda Militar de Alajuela, 1938-1946.

El gráfico anterior contiene las quince piezas musicales más ejecutadas por la Banda Militar de Alajuela entre 1938 y 1946. De esas, las siete primeras son Atardecer Guanacasteco, de Jesús Bonilla, el vals Leda, de Julio Fonseca, el Vals negro, de Gonzalo Sánchez Bonilla, el Vals del recuerdo, el pasillo Santa Clara, Una fiesta en Liberia y la marcha Banda Militar Josefina, estas cuatro últimas también de Jesús Bonilla.

Al continuar con los ejercicios estadísticos, se logró saber cuáles géneros musicales fueron los más utilizados en las programaciones semanales de la banda. El siguiente gráfico mostrará el predominio del vals y la marcha, así como también la fama del bolero, el pasillo, el blues y el foxtrot. Es indispensable aclarar que la popularidad de una obra, de un género específico, afectó el resultado del gráfico, así por ejemplo el vals Leda o el Vals negro fueron muy programados, esto incidió en el hecho de que el vals, como género, aparezca como uno de los más posicionados en esa época. 


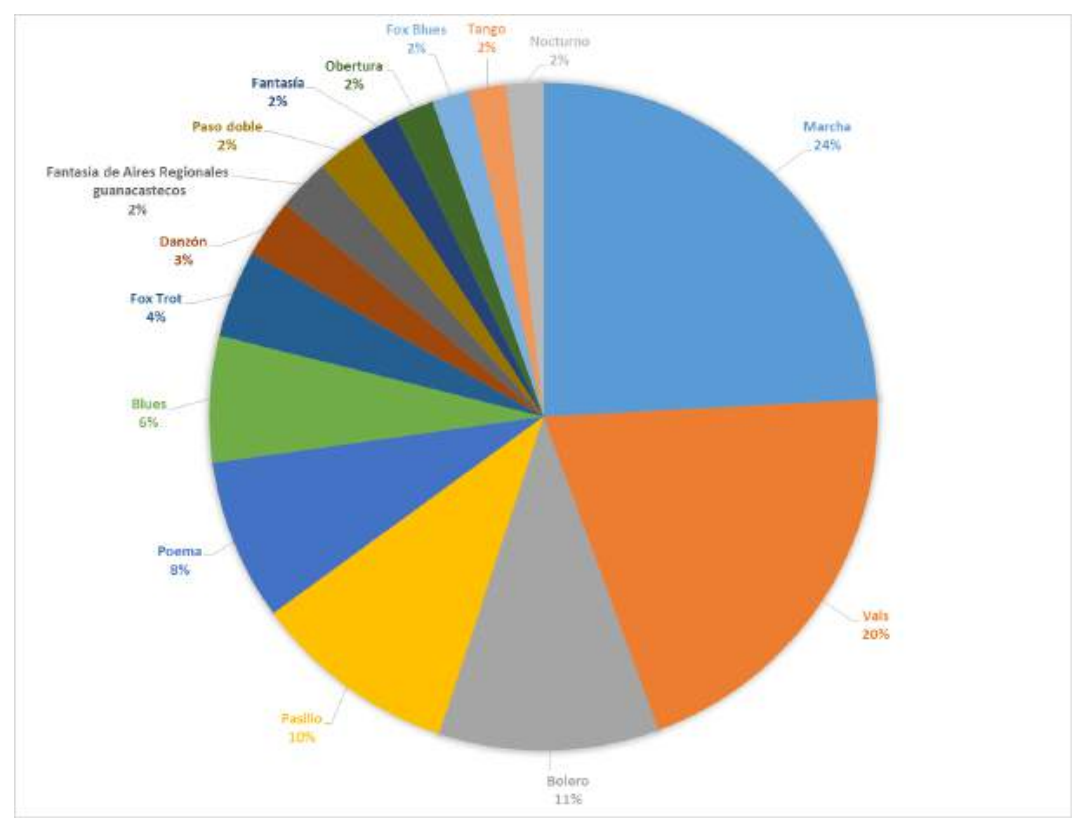

Gráfico 4. Géneros musicales más programados por la Banda Militar de Alajuela, 19381946.

\section{CONCLUSIONES}

Los libros de programas, de control de personal, castigos y otros son fuentes primarias confiables y oficiales que no han sido accedidas. Tampoco son suficientes los trabajos que se enfocaron en las bandas militares, al tomar en cuenta la importancia de estos grupos para el desarrollo musical y cultural de las provincias de Costa Rica.

Cuando se tomó la decisión de estudiar de las bitácoras de trabajo de la Banda Militar de Alajuela, se definió realizar una pequeña reseña histórica de las sucesiones administrativas. Para poder completar la información suministrada por las fuentes bibliográficas, se tuvo que acudir a las bitácoras de diferentes años, en donde se encontraron los registros de altas y bajas de los funcionarios de la banda. De esta forma se lograron ubicar fechas de ascensos de directores y músicos mayores hasta 1969.

La Banda Militar de Alajuela fue un grupo que propició la difusión de obras de autores costarricenses, incluso, fue un medio para que muchos músicos estrenaran sus composiciones. Son muchos los compositores de la presente investigación que no figuran en otros estudios, quizá por ser compositores que destacan con pocas obras o tal vez por tener trayectoria regional y no una 
trayectoria nacional. Así por ejemplo, algunos músicos de la banda también eran compositores. Los directores seguramente ejecutaban sus propias obras, las probaban en los ensayos y quizás en el concierto. Entonces, la banda militar también se convertía en un taller o laboratorio para que los jóvenes autores pudieran probar sus creaciones.

Se tienen varios ejemplos de compositores como Jesús Bonilla, Alfonso Hermes Vanegas, Camilo Chinchilla, entre otros, que fueron músicos de la Banda Militar de Alajuela y aparecían con frecuencia en las programaciones. En la bitácora Inventario de útiles pertenecientes a la Banda Militar de Alajuela, 1905, aparecen programas en donde se puede ver que algunas de las obras de estos compositores se ejecutaron.

Es necesario corroborar que muchas obras de compositores menores seguramente fueron arregladas por compositores competentes que ya tenían experiencia en el campo de la orquestación. Se afirmaría así que algunos músicos solo realizaron un boceto de una idea melódica y armónica, y esta fue desarrollada por los arreglistas o compositores que tenían más experiencia. Queda como tarea averiguar cuáles obras y de cuáles autores fueron arregladas por compositores consolidados.

Las obras del compositor Jesús Bonilla fueron las que más veces sonaron en los conciertos de la Banda Militar de Alajuela de esa época, seguidas por las de Julio Fonseca y Roberto Cantillano, ellos lograron que sus composiciones se ejecutaran con mayor frecuencia. Desde entonces, sus obras permanecen vigentes, debido a eso, sus nombres se han inmortalizado en el imaginario del público que acudió a los conciertos de la bandas de Costa Rica.

Se debe recordar que el director general de bandas era Roberto Cantillano. También se sabe, según una entrevista realizada a la hija de Jesús Bonilla, Jenny Bonilla ${ }^{26}$, que Roberto Cantillano y Jesús Bonilla eran buenos amigos y se dice que Cantillano estrenó bastantes obras de Bonilla, al mismo tiempo que Bonilla programó obras de Cantillano. Este acto de

\footnotetext{
${ }^{26}$ Entrevista realizada a la señora Jenny Bonilla (hija de Jesús Bonilla Chavarría), el sábado 21 de noviembre de 2015.
} 
camaradería puede considerarse valioso en tanto la proyección de música nacional, pues también se constató que Jesús Bonilla, al ser director de la Banda Militar de Alajuela, dio oportunidad a la difusión de obras de varios autores costarricenses, algunos de ellos músicos del sistema de bandas.

Con respecto al repertorio de la Banda Militar de Alajuela, entre 1938 y 1946, se puede concluir que los directores de la agrupación ejecutaron mayoritariamente obras del repertorio internacional. La música de autores costarricenses programada fue menor y los géneros musicales ejecutados mayoritariamente fueron la marcha el vals, el bolero y el pasillo. La marcha militar fue el género más tocado en los conciertos, pero además, las bandas al ser militares, debían ejecutar marchas constantemente. En los libros de programas se puede observar que uno de los servicios más frecuentes era marchar, las bandas debían hacerlo al inicio y al final de las retretas y recreos, en las misas de tropa y en diferentes actividades, por ejemplo, en las procesiones de Semana Santa, en las fiestas patronales, los desfiles, los partidos de fútbol, etc. Por lo tanto, las marchas militares y fúnebres fueron bastante ejecutadas también en lo servicios no contabilizados en este estudio. El otro género preferido fuel el vals: tres de las piezas más ejecutadas por la Banda Militar de Alajuela en ese periodo de tiempo fueron valses: Leda, de Julio Fonseca, el Vals negro, de Gonzalo Sánchez y el Vals del recuerdo, de Jesús Bonilla.

Se debe aclarar que lo denominado Fantasía de aires regionales guanacastecos o Fantasías era como el pot-pourri que agrupaba varias melodías desarrolladas y entrelazadas, según las técnicas de composición académicas, estas fueron una herramienta para dar a conocer y proyectar música regional, por ejemplo, Una fiesta en Liberia y El Sabanero, de Jesús Bonilla, o la Gran Fantasía Sinfónica, de Julio Fonseca, con ritmos tradicionales costarricenses, algunos de la región de Guanacaste. Ese tipo de obras se proyectaron en los conciertos de las bandas.

Como se mencionó anteriormente, se pudo visualizar que, aunque el estudio se refirió estrictamente a la música costarricense, la mayoría de los programas ejecutados incluían más música internacional que nacional. Esto lleva a otra conclusión: la Banda Militar de Alajuela, además de difundir música de autores costarricenses, también dio a conocer a los asistentes de los 
conciertos y a quienes pudieron leer los programas anunciados, música del repertorio internacional, tanto académica, como popular. Por otra parte, los habitantes de las provincias tuvieron acceso a los conciertos de forma gratuita, lo que corrobora que también personas de diferentes estratos sociales pudieron conocer, tanto la música de los grandes maestros europeos, como la de compositores americanos y costarricenses. Quedará pendiente el análisis de los libros de programas de todas las bandas nacionales, donde se incluya el repertorio internacional, eso ayudará a afianzar la siguiente hipótesis: fueron las bandas las que dieron a conocer la música del repertorio universal a la población costarricense de las provincias, desde la segunda mitad del siglo XIX. De esta manera, se puede decir que el Estado costarricense a través de las bandas ha logrado colocar al alcance de los ciudadanos música diversa y variada en una tarea que se definiría como la democratización de la música en Costa Rica.

\section{BIBLIOGRAFÍA}

Acevedo Alvarez Raziel, Guevara Duarte Álvaro. La música tradicional de Guanacaste. Una aproximación escrita. San José Costa Rica: Editorial de la Universidad de Costa Rica, 2007.

Araya, Mauricio. "La Banda Militar de Alajuela y su papel como difusora de música nacional. Análisis de las bitácoras de trabajo 1938-1946. Introducción y resultados preliminaries". Universidad de Costa Rica-Sede de Occidente, Revista Pensamiento Actual-Volumen 16-Número 27, 2016, ISSN Impreso: 1409-0112/ISSN Electrónico: 2215-3586.

Araya, M. (2015). "El Jazz en la música para vientos. Discusiones analíticas en torno a Rhapsody in blue de George Gershwin y Pasillo enredao de Vinicio Meza". Universidad de Costa Rica - Sede de Occidente, Revista Pensamiento Actual - Vol. 15 - No. 25, 2015, ISSN impreso: 1409-0112 / ISSN electrónico: 2215-3586.

Bourdieu, Pierre. Raisons pratiques. París: Seuil, coll. Points, 1996.

Cordero Rodríguez, Enrique. Julio Mata. San José: Ministerio de Cultura, Juventud y Deportes, Dirección de Publicaciones, 1981.

Cuevas Molina, Rafael. "La cultura en Costa Rica, una permanente construcción". Publicado en la Revista Parlamentaria (San José: Asamblea Legislativa, vol. 6, n. 2, diciembre 1998) pp. 151-168. 
Fennell, Frederick. Time and the winds, a Short History of the Use of Wind Instruments in The Orquestra, Band and The Wind Ensamble. Northland Music Publishers, 2009.

Flores, Bernal. La música en Costa Rica. San José: Editorial Costa Rica, 1978.

Flores, Bernal. Julio Fonseca. Datos sobre su vida y análisis de su obra. San José, Costa Rica. Ministerio de Cultura, Juventud y Deportes, 1973.

García Canclini, Néstor. Consumidores y ciudadanos. Conflictos multiculturales de la globalización. México: Grijalbo, 1995.

González Dobles, Jaime. La patria del tico: interpretación del ser costarricense. San José Costa Rica: Logos editorial, Editorial Antares, 1995.

Hernández Valle, Walter. Años de primavera. Memorias de un liceísta. San José, Costa Rica. Editorial Costa Rica, 1995.

Latham, Alison. Diccionario enciclopédico de la música. México D.F: Fondo de Cultura Económica, 2008.

Le Franc Ureña, Roberto. La familia Morales: músicos por tradición. San José, C.R. Editorial UCR, 2009.

Mayor Catalá, Bartolomé. "Harmoniemusik," Revista n²1, Sinfonía Virtual, España, 2011. http://www.sinfoniavirtual.com/revista/021/harmoniemusik.php (consultada el 10 de noviembre de 2013).

Meléndez Chaverri, Carlos. Manuel María Gutiérrez. Ministerio de Cultura, Juventud y Deportes. Depto. De Publicaciones. San José, Costa Rica, 1979.

Molina Jiménez, Iván. Costarricense por dicha: identidad nacional y cambio cultural en Costa Rica durante los siglos XIX y XX. San José, Costa Rica. Editorial Universidad de Costa Rica, 2015.

Monestel Arce, Yehudi. La gran aventura musical de Alcides Prado. Primera edición. San José, Costa Rica. Lara Segura y asociados, 2012.

Prado Quesada, Alcides. Apuntamientos sintéticos sobre la historia y producción musical de Costa Rica. San José: Imprenta Nacional. 1942. 
Sagot Muñoz, Carlos. Música y Significados. Heredia: Editorial de la Universidad Nacional, 1982.

Segura Chaves, Pompilio. Desarrollo musical en Costa Rica durante el siglo XIX. Las Bandas militares. Heredia: Editorial de la Universidad Nacional, 2001.

Small, Christopher. Música, Sociedad, Educación. Traducción de Marta I. Guastavino. Madrid: Alianza Editorial, 1989.

Svatec, Ludmila. Juan Loots y las bandas de música militar. San José: Ministerio de Cultura Juventud y Deportes. Instituto del libro, 1986.

Vargas Cullell, María Clara. De las fanfarrias a las salas de concierto: música en Costa Rica, 1840-1940. San José, Costa Rica: Editorial de la Universidad de Costa Rica, 2004.

Zaldivar Rivera, Mario. Costarricenses en la música. Conversaciones con protagonistas de la música popular 1939-1959. San José, Costa Rica: Editorial de la Universidad de Costa Rica, 2006.

Zaldivar Rivera, Mario. Imágenes de la música popular costarricense 1939-1965. San José, Costa Rica: Editorial de la Universidad de Costa Rica, 2005.

\section{Otras fuentes}

Acuerdo Número XCVII, julio de 1885. Archivo Nacional de Costa Rica.

Banda Militar de Alajuela. Movimiento disciplinario durante el mes de abril, 1930.

Catálogo de música, Banda Militar de Alajuela año 1936. Arreglado por Juan José Leitón.

Cuaderno de castigos del cuerpo de banda, entregado por la comandancia de plaza el 15 de agosto de 1934 y llevado por Arcelio Chávez.

Decreto LXIII. Colección de Leyes y Decretos, folios (208-209), 24 de diciembre de 1845.

Entrevista realizada al señor Antonio González Carballo (exdirector de la Banda de Alajuela) el viernes 20 de noviembre de 2015. 
Entrevista realizada al señor Humberto Barrantes, el domingo 24 de julio de 2016.

Entrevista realizada a la señora Jenny Bonilla (hija de Jesús Bonilla Chavarría), el sábado 21 de noviembre de 2015.

Entrevista realizada a Jorge Sanabria (sobrino de Víctor Manuel Sanabria) por el Dr. Jorge Carmona Ruiz vía correo electrónico, el 30 de octubre de 2014.

Entrevista realizada al señor Piquín Brenes, el sábado 18 de junio de 2016.

Entrevista realizada al señor Víctor Manuel Quesada, el viernes 17 de junio de 2015.

Inventario de útiles pertenecientes a la Banda Militar de Alajuela. Primera fecha indicada en el libro, 1905, en la página 4.

Korte Núñez, Werner. Telecomunicaciones en Costa Rica entre 1900 y 1995. Quintas Jornadas de Investigación: "Bifurcaciones de la Comunicación Social" ECCC, disponible en: http://www.eccc.ucr.ac.cr/recursos/docs/jornadas_2011/Werner_Korte.p df.

Libro de programas, 1 de mayo de 1938, Banda militar de Alajuela.

Libro de programas, 1 de agosto de 1951, Banda Militar de Alajuela.

Nuevo régimen 1936-1940 Alajuela, 8 de mayo, Inventario general de la Banda Militar, Movimiento de Altas, Bajas, descensos, traslados, cambios de instrumentos etc., a cargo de Manuel Alberto Coto Cedeño.

Sistema Nacional de Bibliotecas. Diccionario biográfico. Belarmino Soto. Disponible en: http://www.sinabi.go.cr/diccionariobiografico/biografias/Soto\%20Soto,\% 20Belarmino.html

Sistema Nacional de Bibliotecas. Diccionario Biográfico. Carlos Gutiérrez Gamboa. Disponible en: http://www.sinabi.go.cr/diccionariobiografico/biografias/Gutierrez\%20G amboa,\%20Carlos.html. 